Article

\title{
Simulation-Based Assessment of the Impact of Non-Adherence on Endoxifen Target Attainment in Different Tamoxifen Dosing Strategies
}

Anna Mueller-Schoell 1,2 ${ }^{\mathbb{D}}$, Lena Klopp-Schulze ${ }^{1}$, Robin Michelet ${ }^{1}{ }^{\mathbb{D}}$, Madelé van Dyk ${ }^{3}$, Thomas E. Mürdter ${ }^{4}$, Matthias Schwab ${ }^{5,6,7}$, Markus Joerger ${ }^{8}\left(\mathbb{D}\right.$, Wilhelm Huisinga ${ }^{9}$, Gerd Mikus ${ }^{1}$ and Charlotte Kloft ${ }^{1, *}$

1 Department of Clinical Pharmacy and Biochemistry, Institute of Pharmacy, Freie Universitaet Berlin, 14163 Berlin, Germany; anna.mueller-schoell@fu-berlin.de (A.M.-S.); lena.klopp-schulze@fu-berlin.de (L.K.-S.); robin.michelet@fu-berlin.de (R.M.); gerd.mikus@fu-berlin.de (G.M.)

2 Graduate Research Training Program PharMetrX, 12169 Berlin, Germany

3 College of Medicine and Public Health, Flinders University, Adelaide, SA 5042, Australia; madele.vandyk@flinders.edu.au

4 Dr. Margarete Fischer-Bosch Institute of Clinical Pharmacology, Stuttgart, and University Tübingen, 70376 Tübingen, Germany; Thomas.Muerdter@ikp-stuttgart.de

5 Dr. Margarete Fischer-Bosch Institute of Clinical Pharmacology, 70376 Stuttgart, Germany; Matthias.Schwab@ikp-stuttgart.de

check for updates

Citation: Mueller-Schoell, A.; Klopp-Schulze, L.; Michelet, R.; van Dyk, M.; Mürdter, T.E.; Schwab, M.; Joerger, M.; Huisinga, W.; Mikus, G.; Kloft, C. Simulation-Based Assessment of the Impact of Non-Adherence on Endoxifen Target Attainment in Different Tamoxifen Dosing Strategies. Pharmaceuticals 2021, 14, 115. https://doi.org/ $10.3390 /$ ph14020115

Academic Editor: Joseph Ciccolini Received: 24 December 2020

Accepted: 29 January 2021

Published: 3 February 2021

Publisher's Note: MDPI stays neutral with regard to jurisdictional claims in published maps and institutional affiliations.

Copyright: (c) 2021 by the authors. Licensee MDPI, Basel, Switzerland. This article is an open access article distributed under the terms and conditions of the Creative Commons Attribution (CC BY) license (https:// creativecommons.org/licenses/by/ $4.0 /)$.
6 German Cancer Consortium (DKTK), Partner Site Tübingen, German Cancer Research, 69120 Heidelberg, Germany

7 Departments of Clinical Pharmacology, Pharmacy and Biochemistry, University Tübingen, 72076 Tübingen, Germany

8 Department of Medical Oncology and Hematology, Cantonal Hospital, 9007 St. Gallen, Switzerland; Markus.Joerger@kssg.ch

9 Institute of Mathematics, University of Potsdam, 14476 Potsdam, Germany; huisinga@uni-potsdam.de

* Correspondence: charlotte.kloft@fu-berlin.de

\begin{abstract}
Tamoxifen is widely used in breast cancer treatment and minimum steady-state concen-

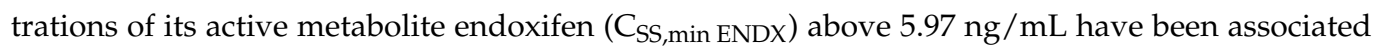

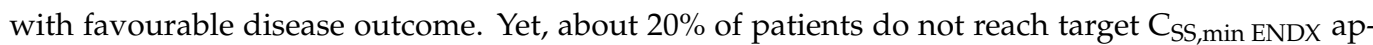
plying conventional tamoxifen dosing. Moreover, $4-75 \%$ of patients are non-adherent, resulting in worse disease outcomes. Assuming complete adherence, we previously showed model-informed precision dosing (MIPD) to be superior to conventional and CYP2D6-guided dosing in minimising

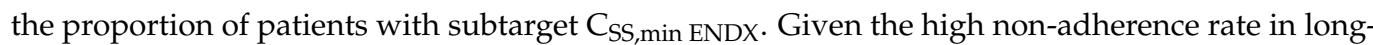
term tamoxifen therapy, this study investigated the impact of non-adherence on $\mathrm{C}_{\mathrm{SS} \text {,min ENDx target }}$ attainment in different dosing strategies. We show that MIPD allows to account for the expected level of non-adherence (here: up to 2 missed doses/week): increasing the MIPD target threshold from $5.97 \mathrm{ng} / \mathrm{mL}$ to $9 \mathrm{ng} / \mathrm{mL}$ (the lowest reported C $\mathrm{SS}$,min ENDX in CYP2D6 normal metabolisers) as a safeguard resulted in the lowest interindividual variability and proportion of patients with subtarget $\mathrm{C}_{\mathrm{SS} \text {, min ENDX }}$ even in non-adherent patients. This is a significant improvement to conventional and CYP2D6-guided dosing. Adding a fixed increment to the originally selected dose is not recommended, since it inflates interindividual variability.
\end{abstract}

Keywords: tamoxifen; non-adherence; model-informed precision dosing; pharmacokinetics; pharmacometrics

\section{Introduction}

Tamoxifen is a selective modulator of the oestrogen receptor (ER), used for the treatment of ER-positive breast cancer in pre- and postmenopausal patients [1,2]. While it is also given in the neoadjuvant, palliative, and preventive setting, it is most often used 
for 5-10 years in the adjuvant setting [1,2]. The metabolism of tamoxifen is complex, involving several polymorphic enzymes such as CYP2D6, CYP3A5, CYP2C9, CYP2C19 as well as sulfotransferases and UDP-glucuronosyltransferases, respectively [3,4]. CYP2D6 plays a major role in the formation of endoxifen, tamoxifen's most relevant and around 100-fold more active metabolite, resulting in a high interindividual variability in endoxifen minimum concentrations at steady-state ( $\mathrm{C}_{\mathrm{SS} \text {, } \min \text { ENDX }}$ [5-7]. Tamoxifen is taken orally at $20 \mathrm{mg}$ once daily (QD) and although convenient, the patient may behave non-adherently. Non-adherence, defined as $<80 \%$ drug intake [8], is significantly associated with treatment failure [9-11]. A therapeutic target for $C_{S S, \min }$ ENDX of $5.97 \mathrm{ng} / \mathrm{mL}$ has been associated with superior survival [6,7]. However, at the conventional dose of $20 \mathrm{mg}$, patients with impaired or loss of CYP2D6 activity are at high risk of being below the target concentration, associated with a $26 \%$ higher breast cancer recurrence rate [7]. Reported adherence rates in adjuvant or preventive tamoxifen treatment vary from $25 \%$ to $96 \%[8,10-16]$ and associations made with non-adherence include young $(<40-60$ years) $[12,15,17]$ and old age (>75-85 years) $[10,12,15,18]$, married status [19], current or previous smoking $[10,20,21]$, node-negative status [10], prior mastectomy [12], prior lumpectomy [15], comorbidities [15], prior history of thromboembolic events [10], sequential treatment assignment with aromatase inhibitors $[10,14]$, adverse events $[16,18,22-24]$ and a low socio-economic background $[19,20]$.

In our previous work, we compared three different tamoxifen early dose finding regimens with an increasing degree of dose individualisation, assuming complete adherence (100\% drug intake) [25]: Conventional dosing, CYP2D6 genotype-predicted phenotypeguided dosing (short: CYP2D6-guided dosing) and model-informed precision dosing (MIPD) [26-28]. Amongst the three strategies, MIPD performed best both in terms of target attainment $(92.8 \%$, compared to $84.0 \%$ and $77.8 \%$ in CYP2D6-guided and conven-

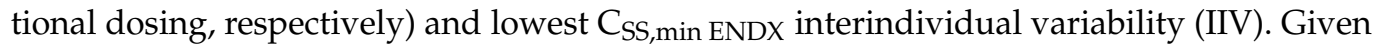
the considerable concern of non-adherence to tamoxifen treatment, this study aimed to explore the impact of later non-adherence on $\mathrm{C}_{\mathrm{SS} \text {, } \min \text { ENDX }}$ target attainment in the three described and two additional modified MIPD early dose finding strategies using stochastic simulations. The simulation results showed that the risk for target non-attainment due to later non-adherence increased with increasing level of dose individualisation during the early dose finding stage. However, targeting the mean $C_{S S, m i n}$ ENDX in CYP2D6 genotype-predicted normal metabolisers (gNM) instead of the proposed therapeutic endoxifen threshold concentration, continued regular therapeutic drug monitoring, and including risk factors for non-adherence in existing pharmacokinetic/pharmacodynamic models used in MIPD can help preserve the value of MIPD in tamoxifen therapy, despite a high prevalence for non-adherence.

\section{Results}

Given the definition of non-adherence $(<80 \%$ drug intake [8], translating into 1.4 missed tamoxifen doses per week), we simulated a large cohort of 10,000 virtual patients (in detail explained in the Methods section) amongst whom $60 \%$ were strictly adherent and $40 \%$ missed one or two consecutive tamoxifen doses per week over a period of six months following an initial six month period of complete adherence (Figure 1). The percentages

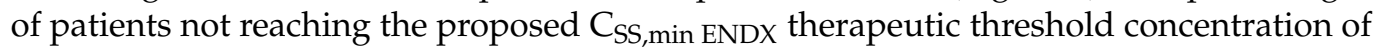
$5.97 \mathrm{ng} / \mathrm{mL}$ [7] in adherent and non-adherent patients were analysed for

(i) Conventional dosing (20 mg QD);

(ii) CYP2D6-guided dosing (gNM: $20 \mathrm{mg}$, gIM: $30 \mathrm{mg}$, gPM: $60 \mathrm{mg}$ QD);

(iii) MIPD targeting the proposed $5.97 \mathrm{ng} / \mathrm{mL}$ (initial CYP2D6-guided dosing for 4 weeks, collection of virtual TDM samples at 2,3 and 4 weeks after treatment start and selection of maintenance dose after week 4 using Bayesian Forecasting);

(iv) MIPD targeting $5.97 \mathrm{ng} / \mathrm{mL}$ (dosing strategy (iii)) when adding $10 \mathrm{mg}$ to each selected dose; and 
(v) MIPD (dosing strategy (iii)) but targeting the lowest reported mean $\mathrm{C}_{\mathrm{SS} \text {, min ENDX in }}$ $\mathrm{gNM}(9 \mathrm{ng} / \mathrm{mL})[29]$.

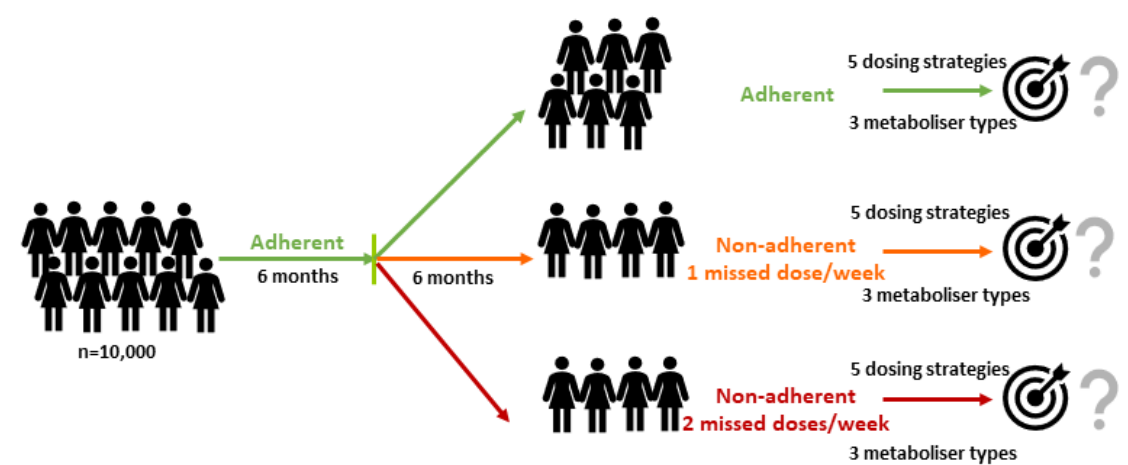

Figure 1. Workflow for the simulation study to assess the impact of two non-adherent scenarios compared to the full adherent scenario ( 0 missed doses/week, top) on endoxifen target attainment for five different dosing strategies comprising genotype-predicted normal metabolisers (gNM), intermediate metabolisers (gIM) and poor metabolisers (gPM).

The dosing strategy (iv) aimed to capture common practice upon observing subtarget concentrations or suspecting non-adherence. Conversely, dosing strategy (v) proposed a more individualised approach to account for later non-adherence in the MIPD early dose finding framework.

Individual dose selections (Supplementary Figures S1-S3), resulting in $\mathrm{C}_{\mathrm{SS}, \min \text { ENDX, }}$

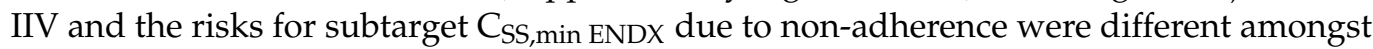
dosing strategies and across CYP2D6 genotype-predicted phenotypes (Figure 2 and Supplementary Table S1).

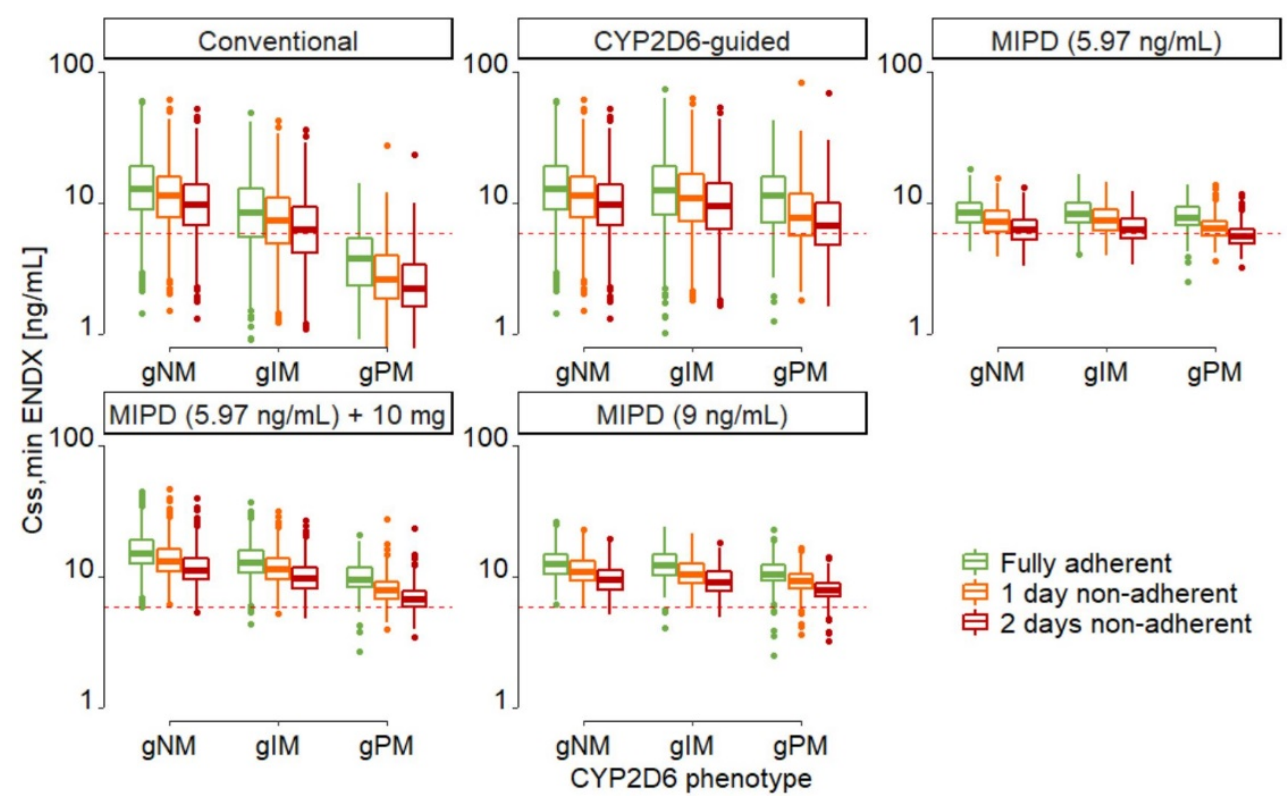

Figure 2. Minimum endoxifen concentrations at steady-state $\left(\mathrm{C}_{\mathrm{SS} \text {,min ENDX }}\right)$ for different CYP2D6 genotype-predicted phenotypes in the five dosing strategies in strictly adherent patients (green), patients missing one dose per week (orange) and patients missing two consecutive doses per week (red) for six months, see Figure 1. Red dashed horizontal line: proposed endoxifen therapeutic threshold concentration $(5.97 \mathrm{ng} / \mathrm{mL})$ [7]; boxes: interquartile line (IQR) including median; whiskers: range from hinge to lowest/highest value within 1.5 IQR; points: data outside whiskers. Abbreviations: gNM, gIM, and gPM: genotype-predicted normal, intermediate, and poor metabolisers, respectively. 


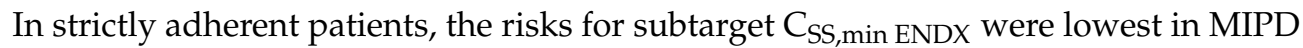
targeting $\mathrm{C}_{\mathrm{SS} \text {, min ENDX }}$ of $9 \mathrm{ng} / \mathrm{mL}$, and in MIPD targeting $5.97 \mathrm{ng} / \mathrm{mL}$ when adding $10 \mathrm{mg}$ to each selected dose. The risk was moderately higher in MIPD targeting $5.97 \mathrm{ng} / \mathrm{mL}$, followed by CYP2D6 genotype-predicted phenotype-guided dosing and conventional dosing (Figure 2 green box-whisker plots, Table 1). The IIV was lowest in MIPD target-

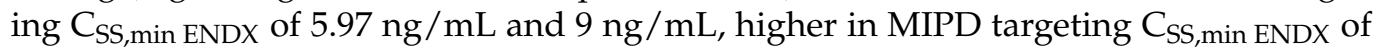
$5.97 \mathrm{ng} / \mathrm{mL}$ when adding $10 \mathrm{mg}$ to each selected dose, and highest in CYP2D6-guided and conventional dosing (Figure 2 and Supplementary Table S1).

Table 1. Percentage of strictly adherent patients at risk (\%) for target non-attainment.

\begin{tabular}{cccccc}
\hline $\begin{array}{c}\text { Patient Sub- } \\
\text { population }\end{array}$ & $\begin{array}{c}\text { Conventional } \\
\text { Dosing }\end{array}$ & $\begin{array}{c}\text { CYP2D6-Guided } \\
\text { Dosing }\end{array}$ & $\begin{array}{c}\text { MIPD (5.97 ng/mL } \\
\text { Target) }\end{array}$ & $\begin{array}{c}\text { MIPD (5.97 ng/mL } \\
\text { Target) } \\
\mathbf{+ 1 0 ~} \mathbf{m g}\end{array}$ & $\begin{array}{c}\text { MIPD (9 } \\
\text { ng/mL Target) }\end{array}$ \\
\hline Overall $^{\dagger}$ & 19.8 & 9.19 & 7.34 & 0.233 & 0.133 \\
gNM & 7.60 & 7.60 & 6.98 & 0.0294 & 0.00 \\
gIM & 28.9 & 10.5 & 7.85 & 0.220 & 0.132 \\
gPM & 81.7 & 16.5 & 7.51 & 2.40 & 1.50 \\
\hline
\end{tabular}

Abbreviations: gXM: genotype-predicted metaboliser; MIPD: model-informed precision dosing, NM: normal metaboliser, IM: intermediate metabolisers; PM: poor metaboliser; ${ }^{+}$: For prevalence of different genotype-predicted phenotypes, see Methods section; bold: dosing strategy with lowest percentage of patients at risk.

When one or two consecutive doses per week were missed, relative risk increases, as assessed by the increase in risk relative to the baseline risk at complete adherence, were highest in MIPD approaches, moderate in CYP2D6-guided dosing, and lowest in conventional dosing (Table 2, Figure 3). The risks for target non-attainment in non-adherent patients were lowest in MIPD targeting $9 \mathrm{ng} / \mathrm{mL}$ and in MIPD targeting $5.97 \mathrm{ng} / \mathrm{mL}$ when adding $10 \mathrm{mg}$ to each selected dose, while they were high in CYP2D6-guided and conventional dosing and highest in MIPD targeting $5.97 \mathrm{ng} / \mathrm{mL}$.

Table 2. Number of patients at risk (\%) for target non-attainment due to missing doses.

\begin{tabular}{|c|c|c|c|c|c|c|c|c|c|c|}
\hline \multirow[b]{2}{*}{$\begin{array}{l}\text { Number of } \\
\text { missed doses }\end{array}$} & \multicolumn{2}{|c|}{$\begin{array}{l}\text { Conventional } \\
\text { Dosing }\end{array}$} & \multicolumn{2}{|c|}{$\begin{array}{c}\text { CYP2D6-Guided } \\
\text { Dosing }\end{array}$} & \multicolumn{2}{|c|}{$\begin{array}{c}\text { MIPD }(5.97 \mathrm{ng} / \mathrm{mL} \\
\text { Target) }\end{array}$} & \multicolumn{2}{|c|}{$\begin{array}{c}\text { MIPD }(5.97 \mathrm{ng} / \mathrm{mL} \\
\text { Target) } \\
+10 \mathrm{mg}\end{array}$} & \multicolumn{2}{|c|}{$\begin{array}{c}\text { MIPD (9 ng/mL } \\
\text { Target) }\end{array}$} \\
\hline & 1 & 2 & 1 & 2 & 1 & 2 & 1 & 2 & 1 & 2 \\
\hline Overall & 26.4 & 33.3 & 14.8 & 21.1 & 22.3 & 42.8 & 0.525 & 3.02 & 0.375 & 1.55 \\
\hline gNM & 13.2 & 19.0 & 13.2 & 19.0 & 22.1 & 42.1 & 0.00 & 0.530 & 0.132 & 1.15 \\
\hline gIM & 36.8 & 45.8 & 14.8 & 21.3 & 20.5 & 40.4 & 0.594 & 2.91 & 0.198 & 1.32 \\
\hline gPM & 90.1 & 92.8 & 32.4 & 41.4 & 36.9 & 65.3 & 5.41 & 29.3 & 4.05 & 7.21 \\
\hline
\end{tabular}

Abbreviations: gNM, gIM, and gPM: genotype-predicted normal, intermediate, and poor metabolisers, respectively. Bold: dosing strategies with lowest percentage of patients at risk having missed one or two doses, respectively.

Increases in risk for target non-attainment due to non-adherence increased with the increasing level of dose individualisation and were inversely proportional to the (absolute) risks for target non-attainment in strictly adherent patients. As expected, the risk of target non-attainment increased with the number of missed doses as well as with the impairment of CYP2D6 function (from gNM to gPM) (Table 1, Figure 3). Both modified MIPD dosing strategies resulted in lower percentages of gNM and gIM at risk. However, compared to MIPD targeting $9 \mathrm{ng} / \mathrm{mL}$, MIPD targeting $C_{S S}$, min ENDX of $5.97 \mathrm{ng} / \mathrm{mL}$ when adding $10 \mathrm{mg}$ to the selected dose resulted in a much higher IIV and a high percentage of non-adherent gPMs at risk. Conversely, MIPD targeting $9 \mathrm{ng} / \mathrm{mL}$ resulted in low risks in non-adherent

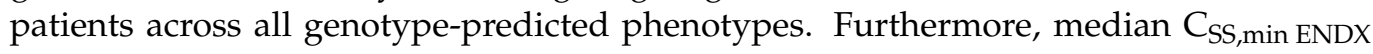

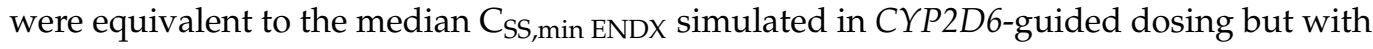
significantly lower IIV (Supplementary Table S1). Thus, increasing the target level to 
$9 \mathrm{ng} / \mathrm{mL}$ presents a safeguard to the uncertainty associated with the patient status and physiology that is not captured and accounted for by covariates. Irrespective of the dose individualisation strategy chosen, strict adherence to tamoxifen intake is most critical in gPM patients.
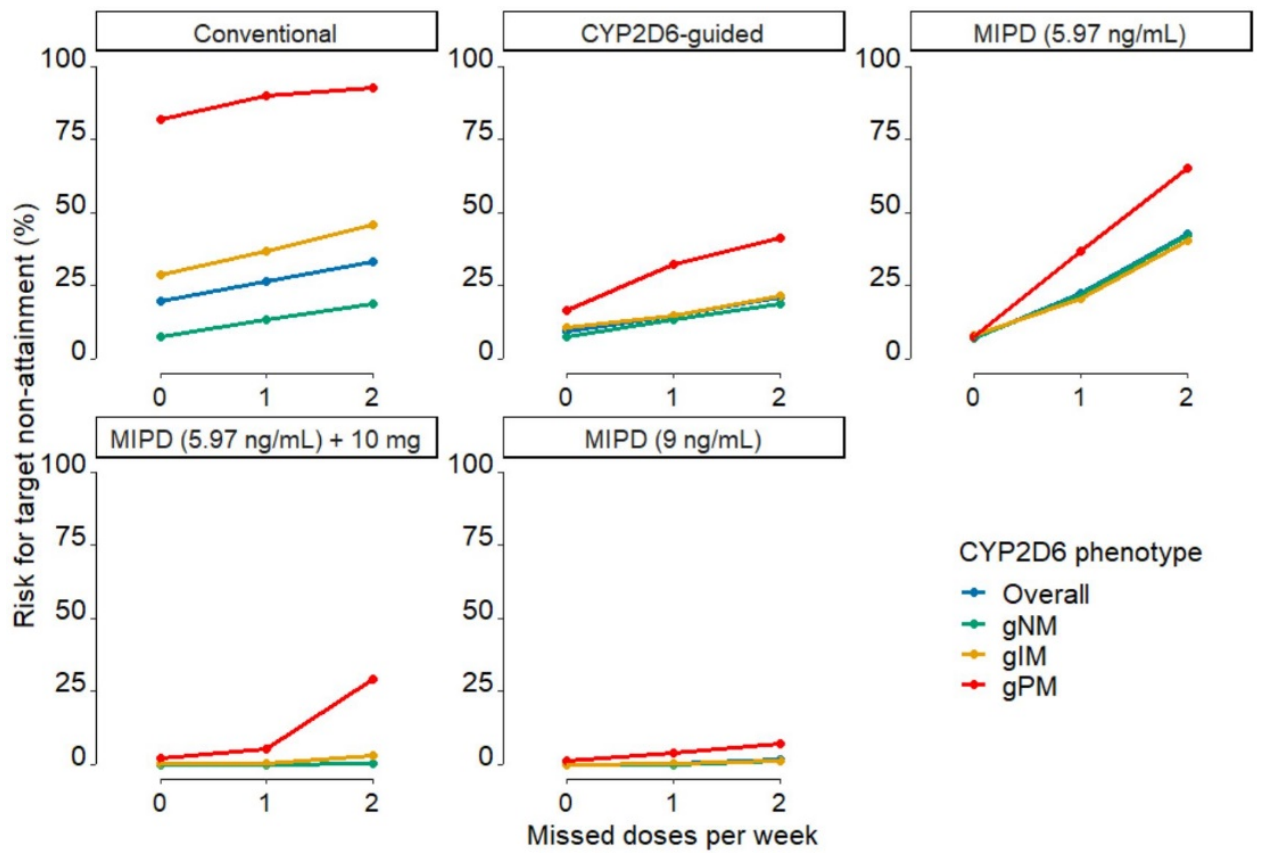

$\rightarrow$ Overall

$\rightarrow$ gNM

$\rightarrow$ gIM

$\rightarrow$ gPM

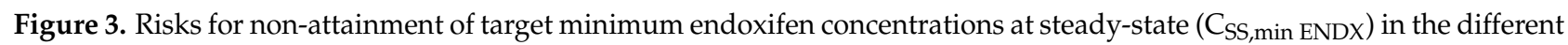
dosing regimens in fully adherent patients, patients missing one dose per week and patients missing two consecutive doses per week for six months. Green: gNM, yellow: gIM, red: gPM, blue: overall. Abbreviations: MIPD: model-informed precision dosing; gNM, gIM, and gPM: genotype-predicted normal, intermediate, and poor metabolisers, respectively.

\section{Discussion}

Non-adherence is often observed in patients undergoing long-term tamoxifen treatment and is a major concern due to its negative impact on disease outcome $[9,10]$. Further-

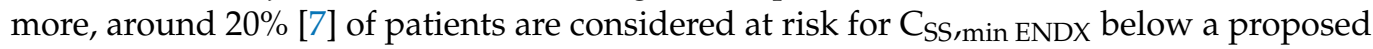
therapeutic threshold due to impaired CYP2D6 activity and additional high unexplained IIV. Of note, tamoxifen adherence could significantly increase the explained variability of endoxifen plasma concentrations in breast cancer patients [30]. An MIPD early dose finding framework has been proposed to increase the proportion of patients reaching target endoxifen concentrations and mitigate the high IIV observed in C SS,min ENDX [25]. However, later non-adherence in long-term therapy is usually not considered in MIPD early dose finding frameworks. Continued regular TDM after initial dose titration could help to identify non-adherent patients early on. However, this service is also expensive, especially in long-term therapies, and is rarely feasible.

In this work, investigating the impact of non-adherence on different dosing strategies, we identified adherence as a crucial factor for the success of MIPD early dose finding strategies. While MIPD targeting the proposed therapeutic threshold concentration of $5.97 \mathrm{ng} / \mathrm{mL}$ is an excellent dosing strategy in strictly adherent patients, it performed worse than CYP2D6-guided dosing in patients missing one dose per week and was worst in patients missing two consecutive doses per week. In fact, almost half $(42.8 \%)$ of MIPD patients targeting the therapeutic target threshold were at risk for subtarget $\mathrm{C}_{\mathrm{SS} \text {, min ENDX }}$ when two consecutive doses were missed after the initial dose finding stage. This finding highlights an important feature of MIPD: precision dosing aims to identify the tailored dose for an individual patient to reach a target exposure. A common assumption is that every dose is taken correctly and, given that the dosing schedule is chosen to result in an exposure 
at but not significantly above the target and no uncertainty on adherence is taken into account, non-adherence will inevitably result in subtarget exposure. In our simulation study, conventional dosing showed the least relative sensitivity to non-adherence as assessed by the increase in risk relative to the baseline risk at complete adherence; however, the risks for target non-attainment were the highest in strictly adherent patients and patients missing one dose per week. Compared to conventional dosing, CYP2D6-guided dosing showed

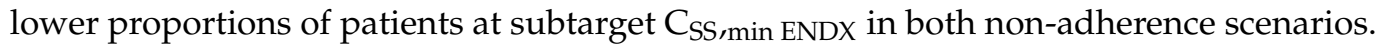
Two factors can explain this: first, CYP2D6-guided dosing allows for the majority of patients to reach exposures above the target concentration. Second, because CYP2D6-guided dosing does not consider the IIV in patients within CYP2D6 genotype-predicted phenotypes, large IIV in CSS, min ENDX can be observed in CYP2D6-guided dosing (Figure 2, large range of whiskers). This results in many individual concentrations being significantly above the target concentration in adherent patients and lower, but not yet subtarget, concentrations in non-adherent patients. Yet, as some individuals experience very high $\mathrm{C}_{\mathrm{SS} \text {,min }}$ ENDX, which can lead to increased frequencies of adverse events [31-33], CYP2D6-guided dosing should not be the dosing strategy of choice.

To further strengthen the advantages of MIPD by implementing a safeguard to nonadherence, we explored two additional MIPD dosing strategies: dosing strategy (iv) adding a fixed increment (here: $10 \mathrm{mg}$ ) to each individual selected dose in MIPD using the original target, as it is commonly done in practice, or a dosing strategy (v) targeting a higher $\mathrm{C}_{\mathrm{SS} \text {,min ENDX }}$ than the proposed therapeutic target threshold, i.e., the mean $\mathrm{C}_{\mathrm{SS} \text {, min ENDX }}$ in gNM. There was a wide range (9.30-34.9 ng/mL) [29,34-38] of reported mean $C_{S S}$,min ENDX in gNM (formerly defined as genotype-predicted extensive metabolisers (gEM)) at conventional dosing from which, as the most conservative approach, we chose the lowest value $(9 \mathrm{ng} / \mathrm{mL}$ [29]) for the increased PK target. In our simulations, both additional dosing strategies resulted in reduced risks due to non-adherence (Figure 3) and over-

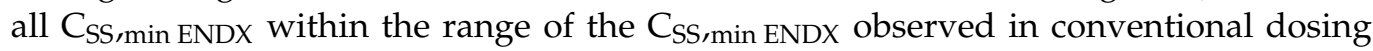
(Figure 2, Supplementary Table S1). Yet, due to the much higher IIV observed in dosing strategy (iv) (additional $10 \mathrm{mg}$ ), introduced by the fixed dose increment, and the large risk increase for gPM when missing two consecutive doses per week, this inferior approach cannot be recommended. To prevent the large increase in IIV, a relative rather than an absolute dose increase would be needed. Based on our simulation results, applying MIPD with a higher target $\mathrm{C}_{\mathrm{SS} \text {,min } \mathrm{ENDX}}$ of $9 \mathrm{ng} / \mathrm{mL}$ in patients with a high risk for non-adherence seems favourable. MIPD targeting a $C_{S S, \min }$ ENDX of $9 \mathrm{ng} / \mathrm{mL}$ results in median $C_{S S, \min }$ ENDX similar to the ones observed in CYP2D6-guided dosing $(12.4 \mathrm{ng} / \mathrm{mL}$ vs. $12.9 \mathrm{ng} / \mathrm{mL}$, Supplementary Table S1). Moreover, due to the reduced IIV $(24.1 \%$ CV vs. $56.8 \%$ CV, Supplementary Table S1) it allows for almost all adherent patients to reach the proposed therapeutic target concentration of $5.97 \mathrm{ng} / \mathrm{mL}$ (99.9\% vs. 90.8\%, Supplementary Table S1) with minimal risk increases due to non-adherence $(1.55 \%$ vs. $21.1 \%$ of patients at risk when missing two consecutive doses per week, Table 2). Of note, the span of tamoxifen doses in dosing strategy (v) is high, ranging from $5 \mathrm{mg}$ QD to $120 \mathrm{mg}$ QD. While we limited our maximum dose to the highest dose tested without additional toxicities [36], the safety of our proposed dosing framework has to be confirmed in a clinical trial before it can be recommended for use in clinical routine.

Additional measures such as continued regular therapeutic drug monitoring after initial therapeutic drug monitoring-based dose titration can aid in promptly identifying non-adherent patients [11] and allows to keep using the original target $\mathrm{C}_{\mathrm{SS} \text {, min ENDX }}$ of $5.97 \mathrm{ng} / \mathrm{mL}$. Finally, existing MIPD approaches for chronic/long-term treatments should be extended (where appropriate) to account for the likelihood of non-adherence and patient characteristics associated with it. Of note, the endoxifen PK target of $5.97 \mathrm{ng} / \mathrm{mL}$ was proposed in a study, which did not account for non-adherence and allowed sample collection up until four years after breast cancer diagnosis [7]. Thus, it cannot be excluded that the cohort analysed in this study contained non-adherent patients. Yet, a similar study in pre-menopausal patients [6], in which non-compliant patients ( $7 \%$ of all patients) 
were excluded for the clinical endpoint analysis, identified a PK target very similar to the target proposed by Madlensky et al. [7] (5.29 ng/mL vs. $5.97 \mathrm{ng} / \mathrm{mL}$ ) Thus, the possible bias due to non-adherent patients in the Madlensky study would be small. Nevertheless, a prospective well-designed trial with careful monitoring of adherence could aid in defining a PK target with no potential bias due to non-adherence. Independent from this, as this study focused on the impact of non-adherence on attaining a certain PK target instead of the exact numerical value of the PK target itself, a change in the PK target would not result in a change to our general findings.

Lastly, based on our pharmacokinetic model, our study was limited to the investigation of the impact of non-adherence on the tamoxifen/endoxifen exposure. Thus, given steady-state attainment under non-adherence, the total duration of non-adherence would not change the results of our study. However, as the total duration of non-adherence certainly impacts the overall risk for breast cancer recurrence, future studies using a pharmacodynamic model should focus on the impact of non-adherence and its duration on clinical endpoints.

\section{Materials and Methods}

A previously published joint parent-metabolite nonlinear mixed-effects pharmacokinetic (PK) model of tamoxifen and endoxifen [39] with its final parameter estimates was used for all simulations in this work. In short, the model consisted of a gut compartment from which tamoxifen was characterised to be absorbed in a first-order process $\left(k_{a}\right)$ with a lag time $\left(t_{l a g}\right)$. Once absorbed, tamoxifen was characterised to distribute within a central compartment $\left(\mathrm{V}_{\mathrm{TAM}} / \mathrm{F}\right)$ and to be either eliminated by linear formation of endoxifen $\left(\mathrm{CL}_{23} / \mathrm{F}\right)$ or by another linear elimination process $\left(\mathrm{CL}_{20} / \mathrm{F}\right)$ comprising other metabolic pathways than to endoxifen. The metabolite endoxifen was characterised to distribute in a central compartment $\left(\mathrm{V}_{\mathrm{ENDX}} / \mathrm{F}\right)$ and to be eliminated in a linear process $\left(\mathrm{CL}_{30} / \mathrm{F}\right)$. Three covariate-PK parameter relationships were identified: the CYP2D6 genotype, implemented as a fractional change model, had a significant impact on endoxifen formation $\left(\mathrm{CL}_{23} / \mathrm{F}\right)$, while patient age and body weight, both implemented as power models, significantly influenced the tamoxifen clearance to metabolites other than endoxifen $\left(\mathrm{CL}_{20} / \mathrm{F}\right)$. Interindividual variability components were implemented on the endoxifen formation and the tamoxifen clearance to other metabolites. Model development and the criteria used for it as well as an extensive covariate analysis, have been explained in detail in [25] and [39], respectively. The simulations were performed in NONMEM 7.4., called through Perl speaks NONMEM (PsN) v. 3.6.2 using the workbench Pirana v. 2.9.7 [40]. Pre- and postprocessing was performed in R v. 3.5.1, accessed through RStudio Version 1.2.1184, using packages Xpose4, ggplot2, plyr, dplyr and zoo.

To perform the simulation analyses, a large number of virtual breast cancer patients ( $n=10,000)$, representing the same frequency of covariates (CYP2D6 genotype, age, body weight) as observed in the clinical PK database ( $n=1388$ patients) used for model development, was generated. Concretely, representing the distribution of CYP2D6 activity scores (AS) [41,42] in the model development dataset [39], the virtual population consisted of $56.6 \%$ CYP2D6 genotype-predicted normal metabolisers (gNM), defined as AS $\geq 1.5$ and including patients with missing AS imputed to AS 2, 37.8\% genotype-predicted intermediate metabolisers (gIM), defined as AS 0.5-1 and 5.6\% genotype-predicted poor metabolisers (gPM), defined as AS 0 [43]. Furthermore, for every virtual patient, a random age and body weight value was sampled with replacement from the age and body weight values recorded in the model development dataset.

The impact of one missed dose or two consecutive missed doses per week on endoxifen target $\left(\mathrm{C}_{\mathrm{SS}, \min \mathrm{ENDX}}>5.97 \mathrm{ng} / \mathrm{mL}\right.$ [7]) attainment was compared for different dosing strategies with different levels of dose individualisation. Slightly modified from a previous investigation [25], the first three dosing strategies were: (i) conventional dosing (20 mg tamoxifen once daily (QD), (ii) CYP2D6-guided dosing (gNM: 20 mg QD, gIM: $30 \mathrm{mg}$ QD (adjusted from $40 \mathrm{mg}$ QD upon classification of AS 1 as gIM instead of gNM [43]), 
PM: $60 \mathrm{mg}$ QD) and (iii) model-informed precision dosing (MIPD). The rationales for dosing strategies (i)-(iii) and detailed information on how MIPD was simulated were described before [25]. In MIPD, the initial dose was based on the CYP2D6 genotype-predicted phenotype and the maintenance dose was selected using Bayesian Forecasting based on individual patient characteristics and three TDM samples taken at 2, 3 and 4 weeks after treatment start. This MIPD design was the result of previous systematic investigations regarding the optimal frequency and time points of TDM sampling [25]. Two additional dosing strategies were explored regarding their potential to increase the forgiveness of MIPD to non-adherence: (iv) MIPD targeting the proposed $\mathrm{C}_{\mathrm{SS} \text {,min ENDX }}$ therapeutic threshold concentration of $5.97 \mathrm{ng} / \mathrm{mL}$ while adding a fixed increment (here: $10 \mathrm{mg}$ ) to each individual dose, as it is common in current clinical practice $[33,37,38,44]$ and (v) MIPD targeting the lowest reported mean endoxifen $\mathrm{C}_{\mathrm{SS} / \mathrm{min}} \mathrm{ENDX}$ in $\mathrm{gNM}(9 \mathrm{ng} / \mathrm{mL})$ [29]. As it is common procedure to increase the dose in fixed increments, i.e., in $10 \mathrm{mg}$ steps due to available tablet strengths, the dosing strategy (iv) aimed to represent the status-quo of dose adjustments to increase drug concentrations in clinical practice $[33,37,38,44]$. Representing the common clinical practice to measure minimum concentrations [45], we chose to collect our virtual TDM samples at the end of a dosing interval. However, as fluctuations in endoxifen concentrations within a steady-state dosing interval are minimal [46], our results are also applicable to different times of sample collection once a steady-state has been attained.

To assess the impact of late non-adherence on endoxifen target attainment, 6 months of full adherence ( $100 \%$ drug intake) were simulated for all dosing strategies $(n=10,000$ patients each), assuring endoxifen steady-state attainment in all patients. Next, based on a previous report [19] and to include a sufficient number of patients in both groups, $60 \%$ of patients were simulated to stay fully adherent for the following 6 months. For the remaining $40 \%$, two scenarios were simulated, in which patients missed either one dose or two consecutive doses per week (corresponding to the non-adherence definition of $<80 \%$ correct medication intake [8] or 1.4 missed doses per week). Of note, in the second 6 months, patients continued to receive the dose determined at "treatment start", i.e., in the first 6 months of complete adherence. No additional TDM samples were taken during the second 6 months. After a total of 12 months, assuring new steady-state attain-

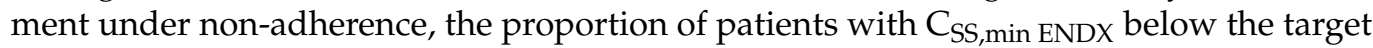
$5.97 \mathrm{ng} / \mathrm{mL}$ (i.e., the number of patients at risk) in the adherent and non-adherent groups in all dosing strategies were assessed overall and for different CYP2D6 genotype-predicted phenotypes specifically.

Supplementary Materials: The following are available online at https:/ / www.mdpi.com/1424-824 7/14/2/115/s1, Figure S1: Range and proportions of the individual dose selection in MIPD targeting the proposed therapeutic target threshold of $5.97 \mathrm{ng} / \mathrm{mL}$, Figure S2: Range and proportions of

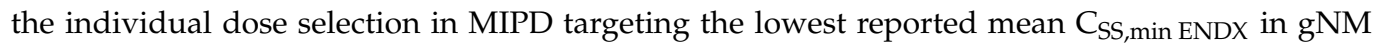
of $9 \mathrm{ng} / \mathrm{mL}$, Figure S3: Range and proportions of the individual dose selection in MIPD targeting the proposed therapeutic target threshold of $5.97 \mathrm{ng} / \mathrm{mL}$ and adding $10 \mathrm{mg}$ to each selected dose, Table S1: Comparison of $\mathrm{C}_{\mathrm{SS} \text {, } m i n} \mathrm{ENDX}$, interindividual variability and proportion in fully adherent patients with subtarget concentrations in the five dosing strategies stratified in the three CYP2D6 genotype-predicted phenotypes with their individual doses.

Author Contributions: Conceptualization, A.M.-S., G.M., and C.K.; methodology, A.M.-S., R.M., G.M., L.K.-S., and C.K.; formal analysis, A.M.-S.; writing-original draft preparation, A.M.-S.; writing—review and editing, A.M.-S., L.K.-S., R.M., M.v.D., W.H., T.E.M., M.S., M.J., G.M., and C.K.; visualization, A.M.-S., C.K., G.M., M.v.D., R.M., W.H.; supervision, G.M., W.H., C.K. All authors have read and agreed to the published version of the manuscript.

Funding: The publication of this article was funded by Freie Universität Berlin. M.S. and T.E.M. were, in part, supported by the Robert Bosch Stiftung, Stuttgart, Germany and the Federal Ministry of Education and Research (BMBF; 01EK1509A), Germany.

Institutional Review Board Statement: Not applicable.

Informed Consent Statement: Not applicable. 
Data Availability Statement: The simulation datasets presented in the current study are available from the corresponding author upon reasonable request.

Acknowledgments: The authors thank the High-Performance Computing Service of ZEDAT at Freie Universität Berlin (https:/ / www.zedat.fu-berlin.de/HPC/Home) for computing time. We are grateful to all clinicians who provided samples for PK studies used to set up the initial models: Patrick Neven (Vesalius Research Center-VIB, University Hospitals Leuven, KU Leuven-University of Leuven, Leuven, Belgium), Stijn L.W. Koolen (Department of Medical Oncology, Erasmus MC Cancer Institute, Rotterdam, The Netherlands), Ron H.J. Mathijssen (Department of Medical Oncology, Erasmus MC Cancer Institute, Rotterdam, The Netherlands), Ellen Copson and Diana Eccles (Cancer Sciences Academic Unit and University of Southampton Clinical Trials Unit, Faculty of Medicine, University of Southampton, and University Hospital Southampton NHS Foundation Trust, Southampton, UK), Sylvia Chen (University Clinical Pharmacology Laboratory, Division of Medical Sciences, Humphrey Oei, Institute of Cancer Research, National Cancer Centre Singapore, Singapore), Balram Chowbay (University Clinical Pharmacology Laboratory, Division of Medical Sciences, Humphrey Oei, Institute of Cancer Research, National Cancer Centre Singapore, Centre for Clinician Scientist Development, Office of Clinical Sciences, Duke-NUS Graduate Medical School Singapore, and SingHealth Clinical Pharmacology Core, Academia, Singapore Health Services, Singapore), Arafat Tfayli (Hematology-Oncology Division, Department of Internal Medicine, Faculty of Medicine, American University of Beirut, Lebanon), and Nathalie K. Zgheib (Department of Pharmacology and Toxicology, Faculty of Medicine, American University of Beirut, Lebanon).

Conflicts of Interest: CK and WH report grants from an industry consortium (AbbVie Deutschland GmbH \& Co. KG, AstraZeneca Ltd., Boehringer Ingelheim Pharma GmbH \& Co. KG, Grünenthal $\mathrm{GmbH}$, F. Hoffmann-La Roche Ltd., Merck KGaA and Sanofi) for the PharMetrX program. CK reports grants for the Innovative Medicines Initiative-Joint Undertaking ('DDMoRe'), from the Federal Ministry of Education and Research as well as the European Commission, all outside the submitted work. LKS is a current employee of Merck KGaA. All other authors declared no competing interests for this work.

\section{References}

1. Cardoso, F.; Kyriakides, S.; Ohno, S.; Penault-Llorca, F.; Poortmans, P.; Rubio, I.T.; Zackrisson, S.; Senkus, E. Early breast cancer: ESMO Clinical Practice Guidelines for diagnosis, treatment and follow-up. Ann. Oncol. 2019, 30, 1194-1220. [CrossRef] [PubMed]

2. Burstein, H.J.; Lacchetti, C.; Anderson, H.; Buchholz, T.A.; Davidson, N.E.; Gelmon, K.A.; Giordano, S.H.; Hudis, C.A.; Solky, A.J.; Stearns, V.; et al. Adjuvant endocrine therapy for women with hormone receptor-positive breast cancer: ASCO clinical practice guideline focused update. J. Clin. Oncol. 2019, 37, 423-438. [CrossRef] [PubMed]

3. Mürdter, T.E.; Schroth, W.; Bacchus-Gerybadze, L.; Winter, S.; Heinkele, G.; Simon, W.; Fasching, P.A.; Fehm, T.; Eichelbaum, M.; Schwab, M.; et al. Activity levels of tamoxifen metabolites at the estrogen receptor and the impact of genetic polymorphisms of phase I and II enzymes on their concentration levels in plasma. Clin. Pharmacol. Ther. 2011, 89, 708-717. [CrossRef] [PubMed]

4. Desta, Z. Comprehensive Evaluation of Tamoxifen Sequential Biotransformation by the Human Cytochrome P450 System in Vitro: Prominent Roles for CYP3A and CYP2D6. J. Pharmacol. Exp. Ther. 2004, 310, 1062-1075. [CrossRef] [PubMed]

5. Sanchez-Spitman, A.B.; Swen, J.J.; Dezentje, V.O.; Moes, D.J.A.R.; Gelderblom, H.; Guchelaar, H.J. Clinical pharmacokinetics and pharmacogenetics of tamoxifen and endoxifen. Expert Rev. Clin. Pharmacol. 2019, 12, 1-14. [CrossRef] [PubMed]

6. Saladores, P.; Mürdter, T.; Eccles, D.; Chowbay, B.; Zgheib, N.K.; Winter, S.; Ganchev, B.; Eccles, B.; Gerty, S.; Tfayli, A.; et al. Tamoxifen metabolism predicts drug concentrations and outcome in premenopausal patients with early breast cancer. Pharm. J. 2015, 15, 84-94. [CrossRef] [PubMed]

7. Madlensky, L.; Natarajan, L.; Tchu, S.; Pu, M.; Mortimer, J.; Flatt, S.W.; Nikoloff, D.M.; Hillman, G.; Fontecha, M.R.; Lawrence, H.J.; et al. Tamoxifen metabolite concentrations, CYP2D6 genotype, and breast cancer outcomes. Clin. Pharmacol. Ther. 2011, 89, 718-725. [CrossRef]

8. Murphy, C.C.; Bartholomew, L.K.; Carpentier, M.Y.; Bluethmann, S.M.; Vernon, S.W. Adherence to adjuvant hormonal therapy among breast cancer survivors in clinical practice: A systematic review. Breast Cancer Res. Treat. 2012, 134, 459-478. [CrossRef]

9. Dezentjé, V.O.; Van Blijderveen, N.J.C.; Gelderblom, H.; Putter, H.; Van Herk-Sukel, M.P.P.; Casparie, M.K.; Egberts, A.C.G.; Nortier, J.W.R.; Guchelaar, H.J. Effect of concomitant CYP2D6 inhibitor use and tamoxifen adherence on breast cancer recurrence in early-stage breast cancer. J. Clin. Oncol. 2010, 28, 2423-2429. [CrossRef]

10. Chirgwin, J.H.; Giobbie-Hurder, A.; Coates, A.S.; Price, K.N.; Ejlertsen, B.; Debled, M.; Gelber, R.D.; Goldhirsch, A.; Smith, I.; Rabaglio, M.; et al. Treatment adherence and its impact on Disease-Free survival in the breast international group 1-98 trial of tamoxifen and letrozole, alone and in sequence. J. Clin. Oncol. 2016, 34, 2452-2459. [CrossRef]

11. Pistilli, B.; Paci, A.; Ferreira, A.R.; Di Meglio, A.; Poinsignon, V.; Bardet, A.; Menvielle, G.; Dumas, A.; Pinto, S.; Dauchy, S.; et al. Serum Detection of Nonadherence to Adjuvant Tamoxifen and Breast Cancer Recurrence Risk. J. Clin. Oncol. 2020. [CrossRef] [PubMed] 
12. Partridge, A.H.; Wang, P.S.; Winer, E.P.; Avorn, J. Nonadherence to adjuvant tamoxifen therapy in women with primary breast cancer. J. Clin. Oncol. 2003, 21, 602-606. [CrossRef]

13. Lundgren, C.; Lindman, H.; Rolander, B.; Ekholm, M. Good adherence to adjuvant endocrine therapy in early breast cancer-a population-based study based on the Swedish Prescribed Drug Register. Acta Oncol. 2018, 57, 935-940. [CrossRef] [PubMed]

14. Wigertz, A.; Ahlgren, J.; Holmqvist, M.; Fornander, T.; Adolfsson, J.; Lindman, H.; Bergkvist, L.; Lambe, M. Adherence and discontinuation of adjuvant hormonal therapy in breast cancer patients: A population-based study. Breast Cancer Res. Treat. 2012, 133, 367-373. [CrossRef] [PubMed]

15. Hershman, D.L.; Kushi, L.H.; Shao, T.; Buono, D.; Kershenbaum, A.; Tsai, W.Y.; Fehrenbacher, L.; Lin Gomez, S.; Miles, S.; Neugut, A.I. Early discontinuation and nonadherence to adjuvant hormonal therapy in a cohort of 8,769 early-stage breast cancer patients. J. Clin. Oncol. 2010, 28, 4120-4128. [CrossRef]

16. Lash, T.L.; Fox, M.P.; Westrup, J.L.; Fink, A.K.; Silliman, R.A. Adherence to tamoxifen over the five-year course. Breast Cancer Res. Treat. 2006, 99, 215-220. [CrossRef]

17. Hsieh, K.P.; Chen, L.C.; Cheung, K.L.; Yang, Y.H. Risks of nonadherence to hormone therapy in Asian women with breast cancer. Kaohsiung J. Med. Sci. 2015, 31, 328-334. [CrossRef]

18. Kahn, K.L.; Schneider, E.C.; Malin, J.L.; Adams, J.L.; Epstein, A.M. Patient centered experiences in breast cancer: Predicting long-term adherence to tamoxifen use. Med. Care 2007, 45, 431-439. [CrossRef]

19. Kimmick, G.; Anderson, R.; Camacho, F.; Bhosle, M.; Hwang, W.; Balkrishnan, R. Adjuvant hormonal therapy use among insured, low-income women with breast cancer. J. Clin. Oncol. 2009, 27, 3445-3451. [CrossRef]

20. Land, S.R.; Cronin, W.M.; Wickerham, D.L.; Costantino, J.P.; Christian, N.J.; Klein, W.M.P.; Ganz, P.A. Cigarette smoking, obesity, physical activity, and alcohol use as predictors of chemoprevention adherence in the national surgical adjuvant breast and bowel project P-1 breast cancer prevention trial. Cancer Prev. Res. 2011, 4, 1393-1400. [CrossRef]

21. Maurice, A.; Howell, A.; Evans, D.G.; O'Neil, A.C.; Scobie, S. Predicting compliance in a breast cancer prevention trial. Breast J. 2006, 12, 446-450. [CrossRef] [PubMed]

22. Day, R.; Ganz, P.A.; Costantino, J.P.; Cronin, W.M.; Wickerham, D.L.; Fisher, B. Health-related quality of life and tamoxifen in breast cancer prevention: A report from the National Surgical Adjuvant Breast and Bowel Project P-1 study. J. Clin. Oncol. 1999, 17, 2659-2669. [CrossRef] [PubMed]

23. Demissie, S.; Silliman, R.A.; Lash, T.L. Adjuvant tamoxifen: Predictors of use side effects, and discontinuation in older women. J. Clin. Oncol. 2001, 19, 322-328. [CrossRef] [PubMed]

24. Grunfeld, E.A.; Hunter, M.S.; Sikka, P.; Mittal, S. Adherence beliefs among breast cancer patients taking tamoxifen. Patient Educ. Couns. 2005, 59, 97-102. [CrossRef] [PubMed]

25. Klopp-Schulze, L.; Mueller-Schoell, A.; Neven, P.; Koolen, S.L.; Mathijssen, R.; Joerger, M.; Kloft, C. Integrated data analysis of six clinical studies points toward model-informed precision dosing of tamoxifen. Front. Pharmacol. 2020, 11, 283. [CrossRef]

26. Darwich, A.S.; Ogungbenro, K.; Vinks, A.A.; Powell, J.R.; Reny, J.L.; Marsousi, N.; Daali, Y.; Fairman, D.; Cook, J.; Lesko, L.J.; et al. Why has model-informed precision dosing not yet become common clinical reality? lessons from the past and a roadmap for the future. Clin. Pharmacol. Ther. 2017, 101, 646-656. [CrossRef]

27. Kluwe, F.; Michelet, R.; Mueller-Schoell, A.; Maier, C.; Klopp-Schulze, L.; van Dyk, M.; Mikus, G.; Huisinga, W.; Kloft, C. Perspectives on Model-Informed Precision Dosing in the Digital Health Era: Challenges, Opportunities, and Recommendations. Clin. Pharmacol. Ther. 2020, 109, 29-36. [CrossRef]

28. Keizer, R.J.; ter Heine, R.; Frymoyer, A.; Lesko, L.J.; Mangat, R.; Goswami, S. Model-Informed Precision Dosing at the Bedside: Scientific Challenges and Opportunities. CPT Pharmacomet. Syst. Pharmacol. 2018, 7, 785-787. [CrossRef]

29. Hertz, D.L.; Deal, A.; Ibrahim, J.G.; Walko, C.M.; Weck, K.E.; Anderson, S.; Magrinat, G.; Olajide, O.; Moore, S.; Raab, R.; et al. Tamoxifen Dose Escalation in Patients With Diminished CYP2D6 Activity Normalizes Endoxifen Concentrations without Increasing Toxicity. Oncologist 2016, 21, 795-803. [CrossRef]

30. Nardin, J.M.; Schroth, W.; Almeida, T.A.; Mürdter, T.; Picolotto, S.; Vendramini, E.C.L.; Hoppe, R.; Kogin, J.P.; Miqueleto, D.; de Moraes, S.D.R.; et al. The Influences of Adherence to Tamoxifen and CYP2D6 Pharmacogenetics on Plasma Concentrations of the Active Metabolite (Z)-Endoxifen in Breast Cancer. Clin. Transl. Sci. 2020, 13, 284-292. [CrossRef]

31. Gallicchio, L.; Lord, G.; Tkaczuk, K.; Danton, M.; Lewis, L.M.; Lim, C.K.; Flaws, J.A. Association of tamoxifen (TAM) and TAM metabolite concentrations with self-reported side effects of TAM in women with breast cancer. Breast Cancer Res. Treat. 2004, 85, 89-97. [CrossRef] [PubMed]

32. Thorén, L.; Lindh, J.D.; Ackehed, G.; Kringen, M.K.; Hall, P.; Bergh, J.; Molden, E.; Margolin, S.; Eliasson, E. Impairment of endoxifen formation in tamoxifen-treated premenopausal breast cancer patients carrying reduced-function CYP2D6 alleles. $\mathrm{Br}$. J. Clin. Pharmacol. 2020, 1-10. [CrossRef] [PubMed]

33. Khalaj, Z.; Baratieh, Z.; Nikpour, P.; Schwab, M.; Schaeffeler, E.; Mokarian, F.; Khanahmad, H.; Salehi, R.; Mürdter, T.E.; Salehi, M. Clinical Trial: CYP2D6 Related Dose Escalation of Tamoxifen in Breast Cancer Patients With Iranian Ethnic Background Resulted in Increased Concentrations of Tamoxifen and Its Metabolites. Front. Pharmacol. 2019, 10, 530. [CrossRef]

34. Irvin, W.J.; Walko, C.M.; Weck, K.E.; Ibrahim, J.G.; Chiu, W.K.; Dees, E.C.; Moore, S.G.; Olajide, O.A.; Graham, M.L.; Canale, S.T.; et al. Genotype-guided tamoxifen dosing increases active metabolite exposure in women with reduced CYP2D6 metabolism: A multicenter study. J. Clin. Oncol. 2011, 29, 3232-3239. [CrossRef] [PubMed] 
35. Martinez de Dueñas, E.; Ochoa Aranda, E.; Blancas Lopez-Barajas, I.; Ferrer Magdalena, T.; Bandrés Moya, F.; Chicharro García, L.M.; Gómez Capilla, J.A.; Zafra Ceres, M.; de Haro, T.; Romero Llorens, R.; et al. Adjusting the dose of tamoxifen in patients with early breast cancer and CYP2D6 poor metabolizer phenotype. Breast 2014, 23, 400-406. [CrossRef]

36. Dezentjé, V.O.; Opdam, F.L.; Gelderblom, H.; Hartigh den, J.; Van der Straaten, T.; Vree, R.; Maartense, E.; Smorenburg, C.H.; Putter, H.; Dieudonné, A.S.; et al. CYP2D6 genotype- and endoxifen-guided tamoxifen dose escalation increases endoxifen serum concentrations without increasing side effects. Breast Cancer Res. Treat. 2015, 153, 583-590. [CrossRef]

37. Kiyotani, K.; Mushiroda, T.; Imamura, C.K.; Tanigawara, Y.; Hosono, N.; Kubo, M.; Sasa, M.; Nakamura, Y.; Zembutsu, H. Dose-adjustment study of tamoxifen based on CYP2D6 genotypes in Japanese breast cancer patients. Breast Cancer Res. Treat. 2012, 131, 137-145. [CrossRef]

38. Fox, P.; Balleine, R.L.; Lee, C.; Gao, B.; Balakrishnar, B.; Menzies, A.M.; Yeap, S.H.; Ali, S.S.; Gebski, V.; Provan, P.; et al. Dose Escalation of Tamoxifen in Patients with Low Endoxifen Level: Evidence for Therapeutic Drug Monitoring-The TADE Study. Clin. Cancer Res. 2016, 22, 3164-3171. [CrossRef]

39. Mueller-Schoell, A.; Klopp-Schulze, L.; Schroth, W.; Mürdter, T.; Michelet, R.; Brauch, H.; Huisinga, W.; Joerger, M.; Neven, P.; Koolen, S.L.W.; et al. Obesity Alters Endoxifen Plasma Levels in Young Breast Cancer Patients: A Pharmacometric Simulation Approach. Clin. Pharmacol. Ther. 2020, 108, 661-670. [CrossRef]

40. Keizer, R.J.; Karlsson, M.O.; Hooker, A. Modeling and simulation workbench for NONMEM: Tutorial on Pirana, PsN, and Xpose. CPT Pharmacomet. Syst. Pharmacol. 2013, 2, 1-9. [CrossRef]

41. Goetz, M.P.; Sangkuhl, K.; Guchelaar, H.J.; Schwab, M.; Province, M.; Whirl-Carrillo, M.; Symmans, W.F.; McLeod, H.L.; Ratain, M.J.; Zembutsu, H.; et al. Clinical Pharmacogenetics Implementation Consortium (CPIC) Guideline for CYP2D6 and Tamoxifen Therapy. Clin. Pharmacol. Ther. 2018, 103, 770-777. [CrossRef] [PubMed]

42. Gaedigk, A.; Simon, S.D.; Pearce, R.E.; Bradford, L.D.; Kennedy, M.J.; Leeder, J.S. The CYP2D6 Activity Score: Translating Genotype Information into a Qualitative Measure of Phenotype. Clin. Pharmacol. Ther. 2008, 83, 234-242. [CrossRef] [PubMed]

43. Caudle, K.E.; Sangkuhl, K.; Whirl-Carrillo, M.; Swen, J.J.; Haidar, C.E.; Klein, T.E.; Gammal, R.S.; Relling, M.V.; Scott, S.A.; Hertz, D.L.; et al. Standardizing CYP2D6 Genotype to Phenotype Translation: Consensus Recommendations from the Clinical Pharmacogenetics Implementation Consortium and Dutch Pharmacogenetics Working Group. Clin. Transl. Sci. 2020, 13, 116-124. [CrossRef]

44. Barginear, M.F.; Jaremko, M.; Peter, I.; Yu, C.; Kasai, Y.; Kemeny, M.; Raptis, G.; Desnick, R.J. Increasing tamoxifen dose in breast cancer patients based on CYP2D6 genotypes and endoxifen levels: Effect on active metabolite isomers and the antiestrogenic activity score. Clin. Pharmacol. Ther. 2011, 90, 605-611. [CrossRef] [PubMed]

45. Mueller-Schoell, A.; Groenland, S.L.; Scherf-Clavel, O.; van Dyk, M.; Huisinga, W.; Michelet, R.; Jaehde, U.; Steeghs, N.; Huitema, A.D.R.; Kloft, C. Therapeutic drug monitoring of oral targeted antineoplastic drugs. Eur. J. Clin. Pharmacol. 2020. [CrossRef]

46. Klopp-Schulze, L.; Joerger, M.; Wicha, S.G.; ter Heine, R.; Csajka, C.; Parra-Guillen, Z.P.; Kloft, C. Exploiting Pharmacokinetic Models of Tamoxifen and Endoxifen to Identify Factors Causing Subtherapeutic Concentrations in Breast Cancer Patients. Clin. Pharmacokinet. 2018, 57, 229-242. [CrossRef] 